\title{
Intrauterine Device
}

National Cancer Institute

\section{Source}

National Cancer Institute. Intrauterine Device. NCI Thesaurus. Code C42771.

A device usually made of plastic or metal, inserted into the uterus to prevent conception. IUCD can be a coil, loop, triangle, or T in shape; its material can be impregnated with a pharmaceutical agent. The primary action of all IUCDs is the induction of a foreign-body reaction within the endometrium. This sterile inflammatory process is toxic to gametes, primarily spermatozoa, and effectively prevents viable sperm from passing into the fallopian tubes. The copper-bearing device has an independent toxic effect on spermatozoa. The progestin-releasing devices produce changes in endometrial architecture and function that reduce the potential for implantation of a fertilized egg. The progestin effect on the cervical mucus also reduces the penetrability of sperm. 